
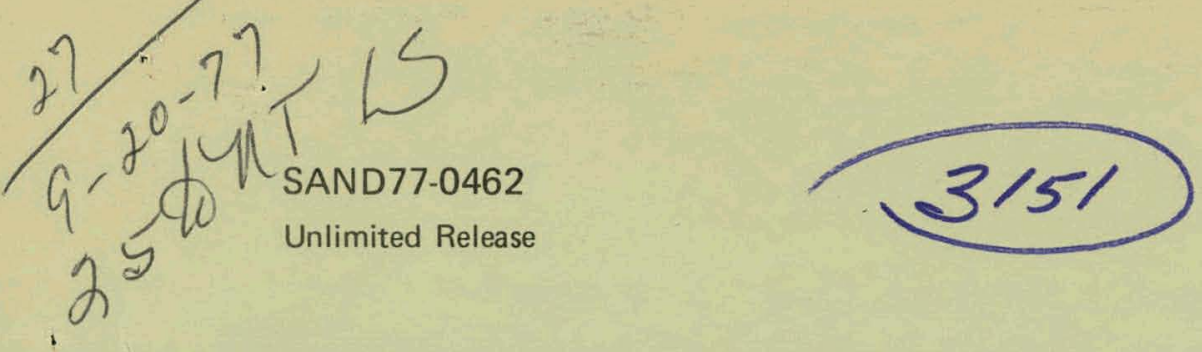

\title{
Circuit Designs for Measuring Reactor Period, Peak Power, and Pulse Fluence on TRIGA and Other Pulse Reactors
}

Robert D. Meyer, Frank V. Thomé, Robert L. Williams

Prepared by Sandia Laboratories, Albuquerque, New Mexico 87115

and Livermore, California 94550 for the United States Energy Research

and Development Administration under Contract AT $(29-1)-789$

Printed August 1977 


\section{DISCLAIMER}

This report was prepared as an account of work sponsored by an agency of the United States Government. Neither the United States Government nor any agency Thereof, nor any of their employees, makes any warranty, express or implied, or assumes any legal liability or responsibility for the accuracy, completeness, or usefulness of any information, apparatus, product, or process disclosed, or represents that its use would not infringe privately owned rights. Reference herein to any specific commercial product, process, or service by trade name, trademark, manufacturer, or otherwise does not necessarily constitute or imply its endorsement, recommendation, or favoring by the United States Government or any agency thereof. The views and opinions of authors expressed herein do not necessarily state or reflect those of the United States Government or any agency thereof. 


\section{DISCLAIMER}

Portions of this document may be illegible in electronic image products. Images are produced from the best available original document. 

Corporation.

\section{NOTICE}

This report was prepared as an account of work sponsored by the United States Government. Neither the United States nor the United States Energy Research \& Development Administration, nor any of their employees, nor any of their contractors, subcontractors, or their emplovees, makes any warranty, express or implied, or assumes any legal liability or responsibility for the accuracy, completeness or usefulness of any information, apparatus, product or process disclosed, or represents that its use would not infringe privately owried rights.

Printed in the United States of America

Available from

National Technical Information Service

U.S. Department of Commerce

5285 Port Royal Road

Springfield, VA 22161

Price: Printed Copy $\$ 3.50 ;$ Microfiche $\$ 3.00$ 
SAND77-0462

Unlimited Release

Printed August 1977

\title{
CIRCUIT DESIGNS FOR MEASURING REACTOR PERIOD, PEAK POWER; AND PULSE FLUENCE ON TRIGA AND OTHER PULSE REACTORS
}

Robert D. Meyer

Solar Total Energy Test Facility Division 5712

Frank V. Thomé

Intrusion Detection and Assessment Technology Division 1739

Robert L. Williams

Reactor Applications Division 5451

Sandia Laboratories

Albuquerque, NM 87115

\begin{abstract}
Inexpensive circuits for use in evaluating reactor periods, peak power, and pulse fluence (NVT), are presented. Besides being low in cost, these circuite are easily aseembled and oalibratcd, and uperate with a high degree of accuracy. The positive period measuring system has been used in evaluating reactivity additions as small as 5 cents (with an accuracy of \pm 0.1 cent) and as large as $\$ 4.50$ (accuracy \pm 2 cents). Reactor peak power is measured digitally with a system accuracy of $\pm 0.1 \%$ of a 10 volt input $( \pm 10 \mathrm{mV})$. The NV'T circuit measures over a 2-1/2 decade range, has 3-placo resolution, and an accuracy of better than $1 \%$.
\end{abstract}

This report was prepared as an eccount of work

sponsored by the United States Government. Neither

the United States nor the United States Energy

Research and Development Administration, not any of

subcontractors, os their of their contractors.

warranty, express or implied, of assumes any legal

lability or responsibility for the socuracy, completenes

or usofulness of any tinforitistivn, apparatus, product of

process disclosed, ar represents that its use would not

infringe privately owned rights. 


\section{A CKNOWLEDGMENT}

The author wishes to thank H. L. Kefauver, 5423, for his assistance in the design of the logic circuitry which controls the display in the peak power detector. He also built the first working circuit and developed the method for calibrating the peak detector. 


\section{CONTENTS}

$\begin{array}{lr} & \frac{\text { Page }}{\text { Introduction }} \\ \text { Circuit Descriptions and Calibration } & 7 \\ \quad \text { Reactor Period Measuring System } & 7 \\ \quad \text { Reactor Peak Power Detector } & 7 \\ \quad \text { Reactor Pulse Fluence Detector } & 10 \\ \text { Summary } & 13 \\ \text { APPENDIX - Sandia Drawings } & 18\end{array}$

\section{ILLUSTRATIONS}

$\underline{\text { Figure }}$

1. Present ACPR Reactor Period Measuring System $r$

2. Proposed ACPR Reactor Period Measuring System 11

3. ACPR Reactor Period Measuring Voltage Sensor 11

4. ACPR Reactor Peak Power Detector 12

5. ACPR Pulse Fluence (NVT) Measuring Circuit $\quad 15$

6. NVT Peak Detector Response for Different Storage Rapacitor 3izes 16

7. NVT Feak Detector Response for Different. Pulse Sizes 17

TARIES

Table

I ACPR Reactor Period Measuring System Specifications and Costs 10

II ACPR Reactor Peak Power Detector System Specifications and Costs 14 


\section{CIRCUIT DESIGNS FOR MEASURING REACTOR PERIOD, PEAK POWER, AND PULSE FLUENCE ON TRIGA AND OTHER PULSE REACTORS}

Introduction

Reactor pulse evaluation circuits are not readily available as off-the-shelf instrumentation. Circuits were designed specifically for the Annular Core Pulse Reactor (ACPR) ${ }^{1}$ but are applicable to all TRIGA pulse :reactors and other types of pulse reactors. Of particular interest in evaluating a single reactor pulse is the prompt reactor period or e-folding time, the peak reactor power that the reactor achieves, and the resultant pulse fluence (NVT or neutrons $/ \mathrm{cm}^{2}$ ) delivered to an experiment.

The Annular Core Pulse Reactor is a TRIGA-type reactor using cylindrical uranium-zirconium hydride fuel-moderator elements. Some of the significant features are its large dry central cavity, close fuel element:spacing producing an undermoderated core and a "harder" neutron energy spectrum, and its high pulse capability. The maximum pulse capability is produced by a reactivity addition of $\$ 4.50$ delivering a total fluence of about $3.6 \times 10^{15}$ neutrons $/ \mathrm{cm}^{2}$ to the central cavity, a pulse width at half maximum (PWHM) of $4.5 \mathrm{~ms}$, minimum prompt period of $1.280 \mathrm{~ms}$, and a peak reactor power of $15,000 \mathrm{MW}$.

\section{Circuit Descriptions and Calibration}

\section{Reactor Periòd Measuring System}

As may be seen in Figures 1 and 2, a current signal originating from à neutron detector is vindilluned to provide a linear voltage output of $U$ to $b$ volts (or $U$ to $10 \mathrm{~V}$ ) for each range (a decade) of reactor power. The power level range is selected before the pulse to provide a "window" of power level in which to sample for a minimum prompt period. The larger the expected pulse size the higher the sample range. This voltage signal is applied to the Calex Voltsensor which is the heart of the system. Adjusting the low and high setpoint potentiometers on the Voltsensor for a factor of " $\mathrm{e}$ " (2.718) in voltage separation, will cause an incoming signal to be converted to independent output trigger signals that start and stop a time interval counter. The time reads directly in reactor period and is easily convertible'to reactivity.

\footnotetext{
${ }^{1}$ L. L. Bonzon, F. M. Morris, and F. V. Thomé, "Annular Core Pulse Reactor (ACPR): Experimenter's Manual," SLA-73-1017, Sandia Laburaturies, Ocluber' 1974.
} 
HEWLETT -PACKARD

TIMER-COUNTER MODEL 5326B

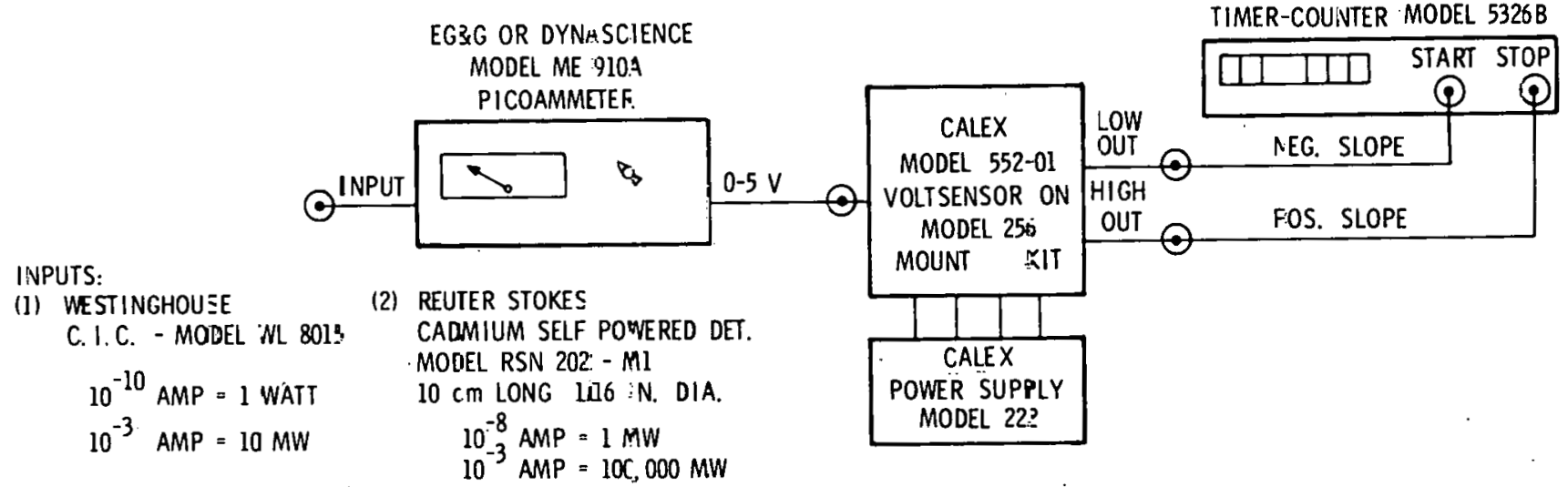

Figure L. Preseat ACPR Reactor Period Measuring System

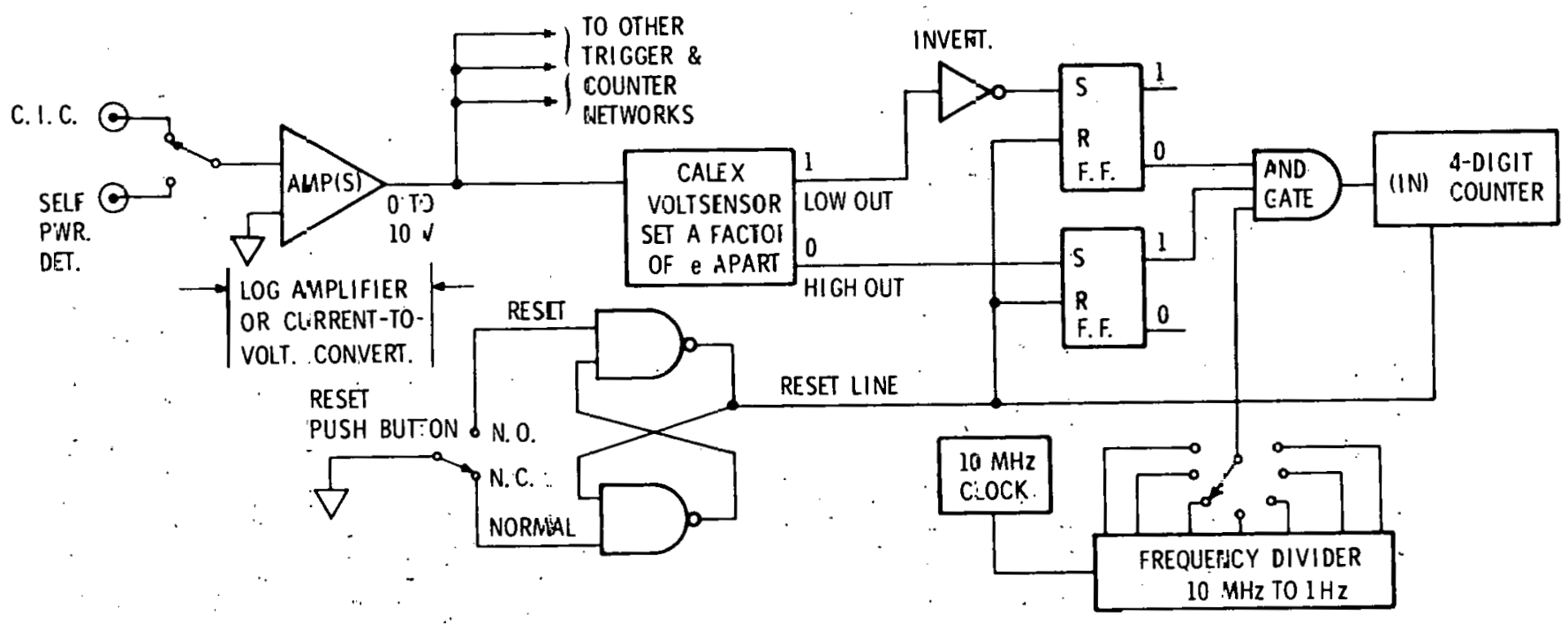

Figure 2. Proposed ACPR Reactor Period Measuring System 
Two identical systems were employed in a recent ACPR recalibration where the period measuring systems were used in determining fuel element worths and in calibrating the transient bank from $0 \notin$ through prompt critical to $\$ 4.50$. The system provided reproducible results and had an accuracy of about $\pm 0.1 \notin$ for 5 -cent reactivity additions and $\pm 2 \notin$ for $\$ 4.50$ pulses.

Several techniques are available for measuring reactor period. The most desirable is a system like that shown in Figure 2 but with three additional period indications covering four decades of reactor power. A single detector system will suffice for all four decades where the current-to-voltage converter or log amplifier determines the power level range(s). More than one channel and one range of period information is required to adequately determine stable periods in the supercritical but sub-prompt-critical region and to evaluate the area of minimum prompt period for large pulses. Reactor periods in the sub-prompt-critical region are influenced by the prompt neutron fraction and by reactor heating. Periods, therefore, must be evaluated in the "stable". region where the period is slower than that immediately following the reactivity addition, but faster than that prior to the onset of fuel heating. Super-prompt-critical periods on TRIGA reactors, and other variable heat capacity reactors, present other problems in measurement since the minimum period occurs at different power levels dependent on the pulse size. The four periods measured over the four-decade range allow for proper evaluation of the data and provide important information concerning the fuel heating and the negative reactivity feedback. It also can aid in determining whether all available reactivity is inserted for a given pulse.

The cost of a two-channel (four decades per channel) system is not prohibitive since the largest portion of the cost is for the detectors and any period system requires this purchase. Table I (costs) illustrates that each complete channel can be built for about $\$ 2000$. The table also provides important specifications on the Calex Voltsensor.

Calibration -- Calibration of the Calex Voltsensor is the only section of the system that requires some caution. The objective is to set the low and high trip points a factor of e apart (e.g., at $1 \mathrm{~V}$ and $2.718 \mathrm{~V}$ ). The high and low setpoints (pots 1 and 2), as seen in Figure 3, produce a voltage signal at their respective connectors that is indicative of the voltage trip points. A digital voltmeter capable of measuring voltage to four significant figures is necessary to get the required period resolution. These measured voltage polarities are opposite that of the actual trip point polarity. Measured voltages at these high and low set connectors is not necessarily the true voltage trip point and should be checked by very accurately applying a known increasing voltage and observing the proper Voltsensor output trip. Several iterations and the readjusting of pots 1 and 2 may be necessary to establich the truc trip sellings. Read and record the settings with the input disconnected because applied voltages slightly affect the low and high setpoints as measured at the set connector. A periodic check of these set voltages is all that is necessary to assure proper tripping. When ordering the Calex Model 256 Mounting Kit, specify the voltage trip range (e.g., 0 to +5.0 volts) and the factory, installs the proper size resistors. Refer to. Sandia $\mathrm{Dwg} \mathrm{T} 40887$ in the Appendix of this report for details on connecting the Calex system. 
ACPR Reactor Period Measuring System Specifications and Costs

Calex Specifications:

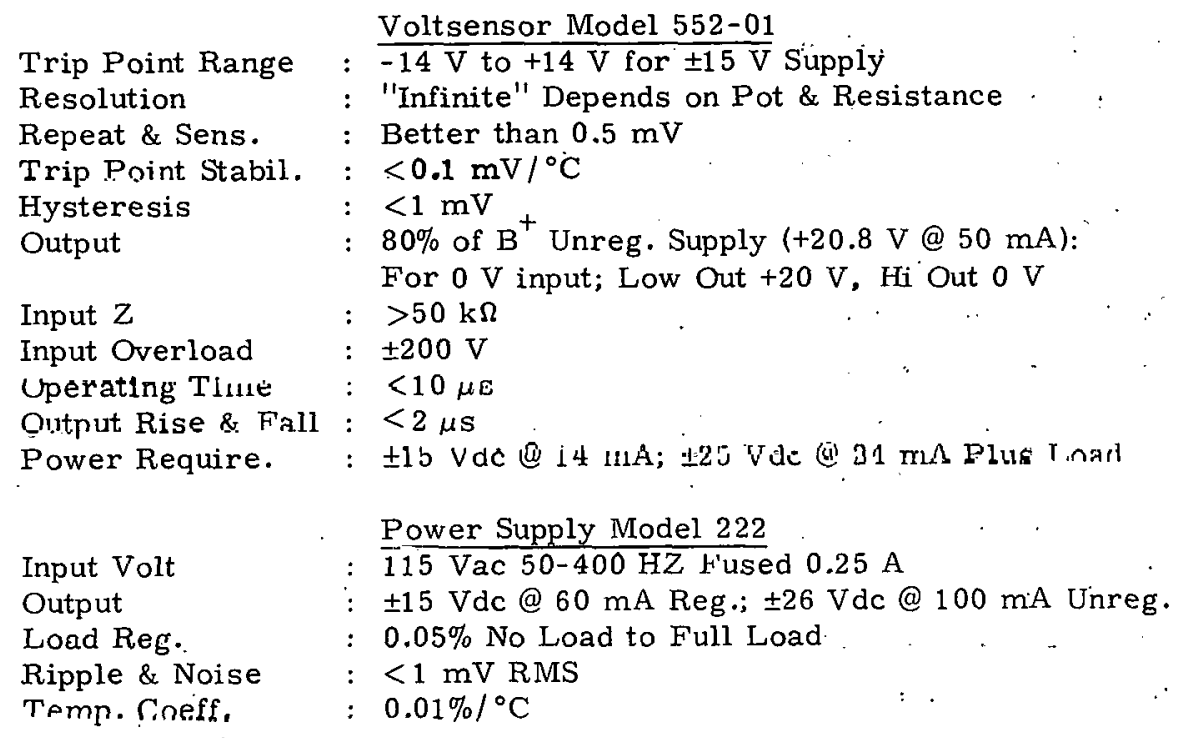

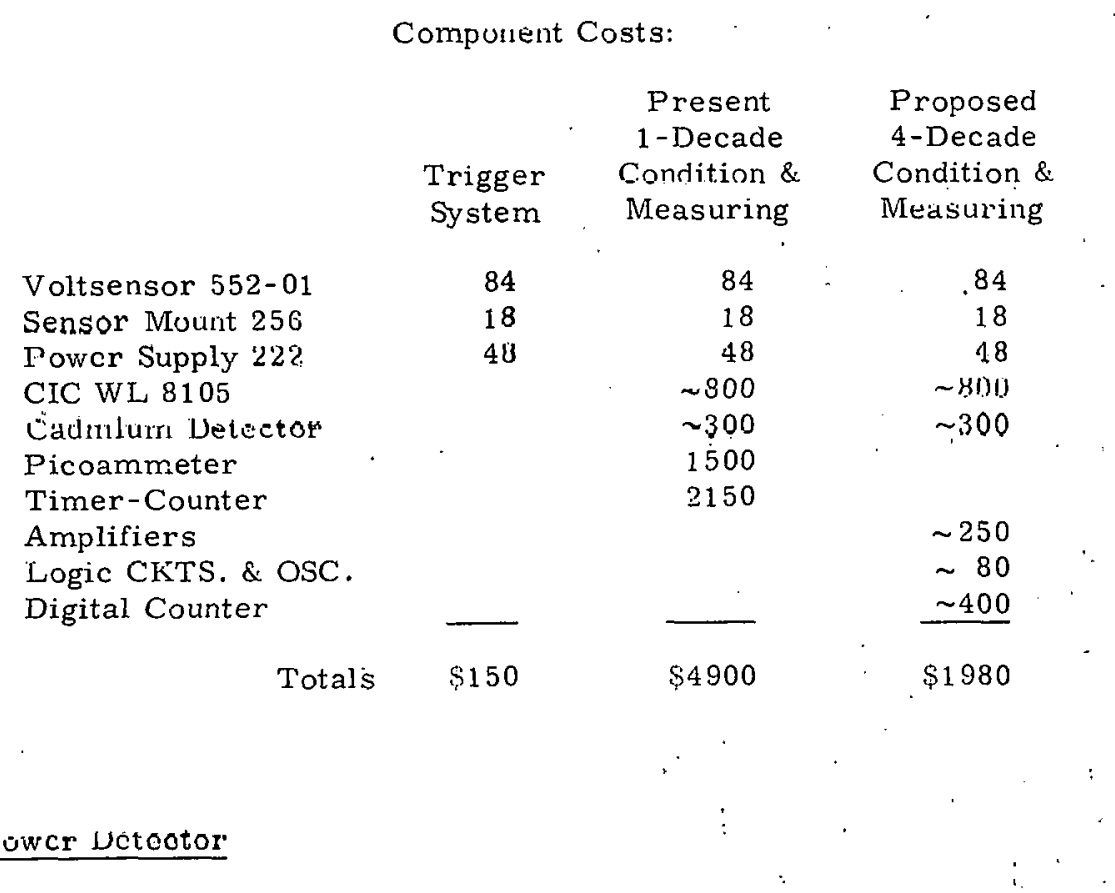

Reactor peak power information is useful in evaluating a reactor pulse. From peak power information the PWHM and peak flux (NV) can be inferred. The most critical aspect of an inference from peak power information is that of the detector lucation. The detector must be insensitive to experiment interactions and core flux profile shifts due to control and/or transient rod unbalances. 


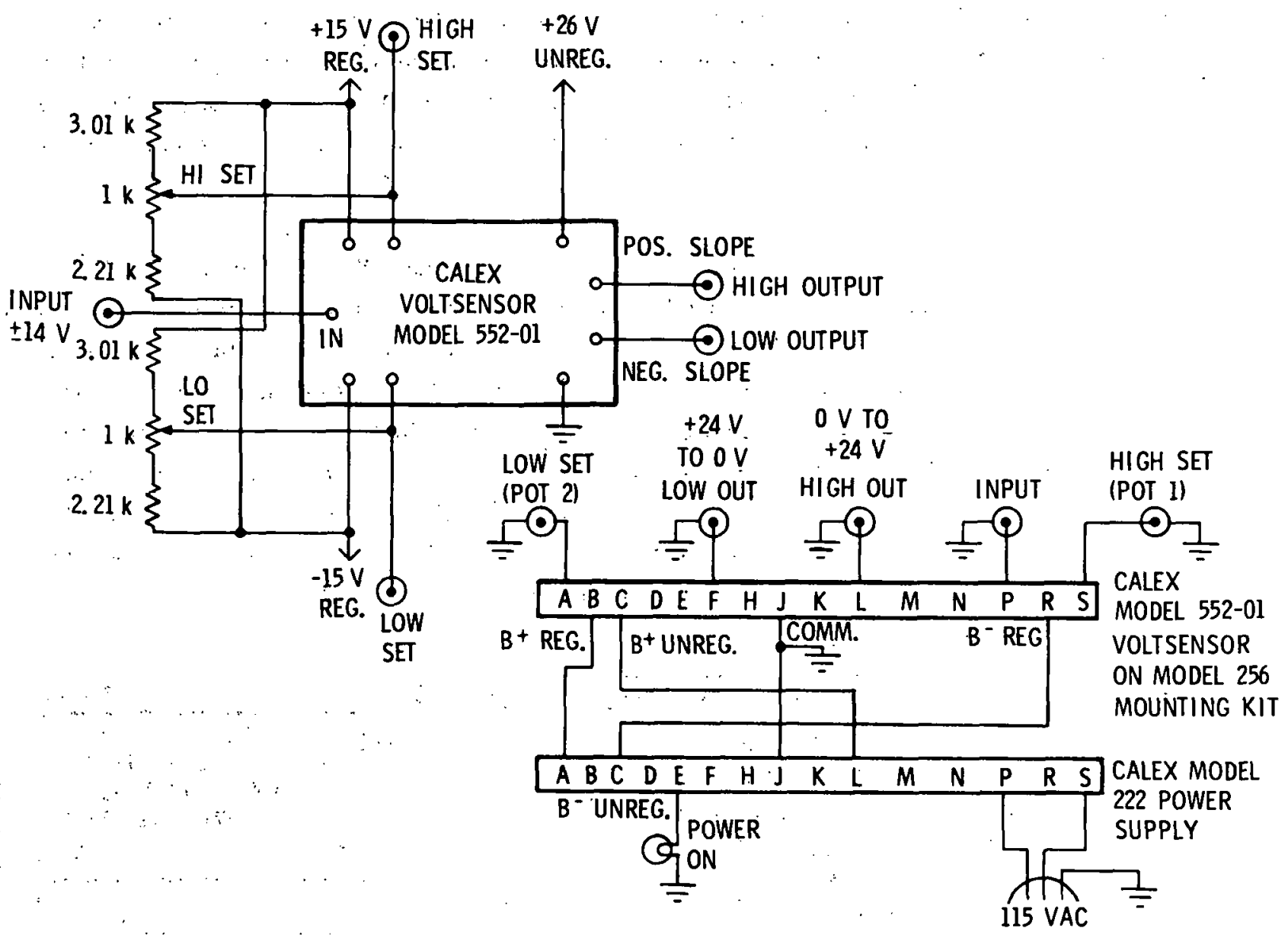

Figure 3. ACPR Reactor Period Measuring Voltage Sensor

Figure 4 il.lustrates a circuit design capable of detecting peak powers and holding that information on a digital panel meter until manually reset. The circuit does not show a specific input signal but should adapt to most TRIGA consoles with a reactor pulse capability or any conditioned signal between 0 and +10 volts. Central to the design is a Burr-Brown peak detector and a digital panel meter with a capability to hold a displayed reading on command. The remainder of the circuitry consists of logic to control the different modes of operation. Burr-Brown's peak detector is of the $\mathrm{R}-\mathrm{C}$ memory type with a very low "droop rate" (specifications state droop at $\pm 5 \mathrm{mV} / \mathrm{s}$; but it measures at about $2 \mathrm{mV} / \mathrm{s}$ ). It is this low droop rate, plus its capability to slew at a fast rate, provide a "status" signal of a peak event, and accurately transfer the input signal to the output, that makes such a:detector ideal for reactor pulse application.

The peak detector is controlled by using compatible integrated circuitry. The logic mode (peak detect or reset) is controlled through a Local/Remote selector switch. This switch, in the LOCAL position, permits resetting of the peak detector with a pushbutton switch and contactbounce-elimination circuit and, on release of the button, returns the system to the peak detect mode. The system then awaits an incident pulse to evaluate. Noise on the input line can cause the 
system to react as if it has seen a pulse. To overcome the noise problem the REMOTE control mode can be selected in which case the system is held in reset until the reactor power level reaches $1 \mathrm{~kW}$ or some other arbitrary power level. The $1 \mathrm{~kW}$ reset control operates through, a flip-flop bistable to prevent the system from an automatic reset following a pulse. One pushbutton resets for both modes.

Digital power-level indication is displayed on the Non-Linear Systems, Inc. Model PM-4. Its $\pm 10 \mathrm{~V}$ four-digit display provides more than'enough resolution, while its "hold" feature provides a means for maintaining the displayed signal by shorting 2 terminals. To hold the display at the proper time, a signal from the peak detector "Status" terminal is fed to a monostable multivibrator; this multivibrator is used to invert the signal slopes for use in the timer. "The One Shot Timer is also a monostable multivibrator, but its purpose is to adjust the time from peak detect to meter hold. This is important because the digital meter must have time to condition, settle, and display the signal which takes about 2 seconds. During this 2 seconds the peak detector output has "drooped" 4 to $10 \mathrm{mV}$. The remaining circuitry is for driving and resetting the relay.

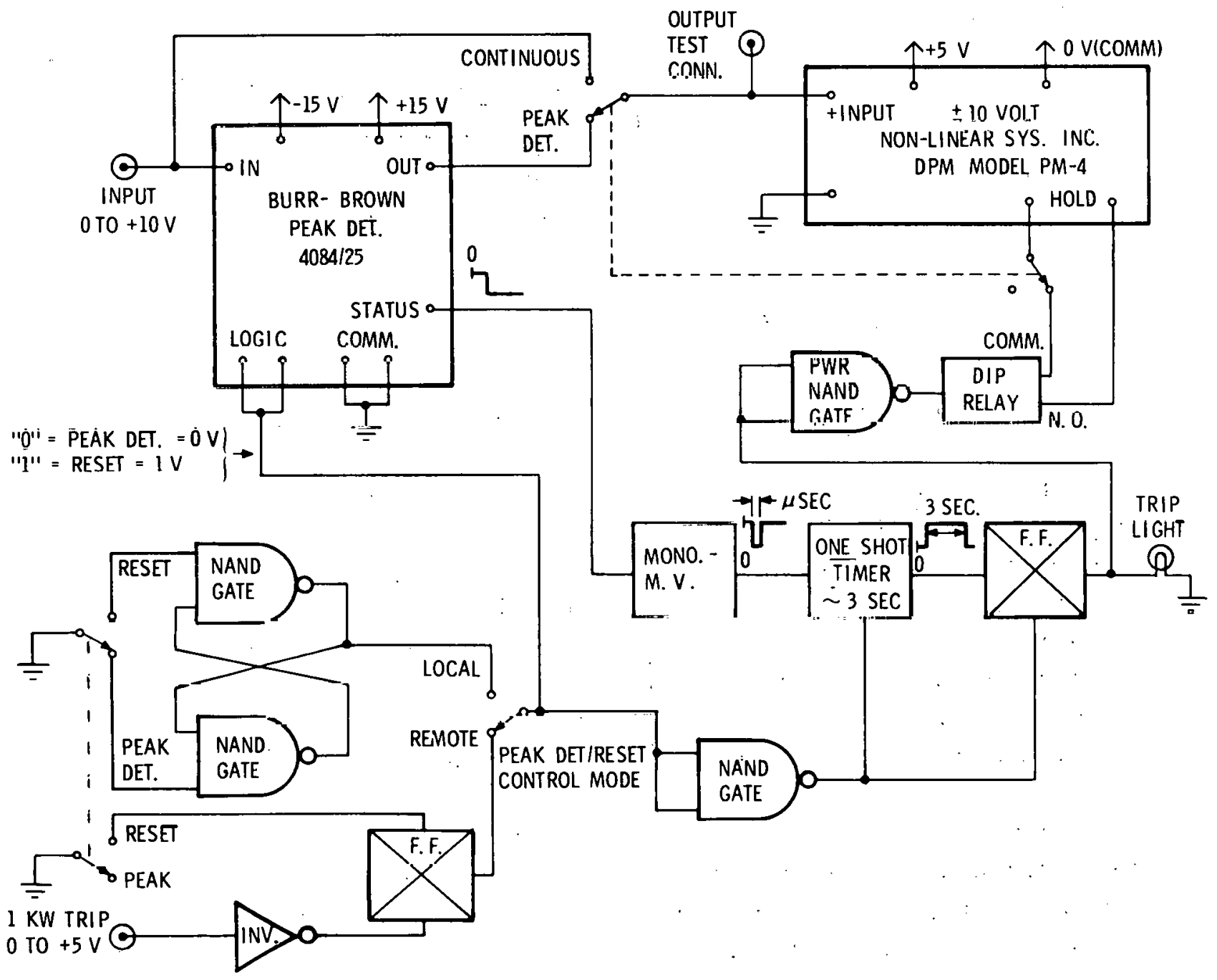

Figure 4. ACPR Reactor Peak Power Detector 
Table II illustrates some of the systems primary component capabilities and limitations. The cost estimate is for a do-it-yourself fabrication and is very inexpensive compared to available general-purpose, peak-reading voltmeters.

Calibration -- Calibration of the peak detector system consists of applying precisely $9 \mathrm{kV}$ at the input connector with the continuous/peak detect selector in the CONTINUOUS position, then adjusting the $R-1$ potentiometer inside the meter until the display reads 9000 . The $R-2$ resistor (see Dwg. T40885 in the Appendix) can be changed to provide a time other than 3 seconds by selecting a resistor that produces a delay, within limits, of 1 second per megohm of resistance. This change may be desirable for a meter other than the P I -4 . There are no other calibrations necessary to place this system into operation. Careful attention to the instructions provided with the Burr-Brown peak detector and the PM-4 digital meter is important for wiring information, and for multiple channel applications.

\section{Reactor Pulse Fluence Detector}

Pulse fluence (NVT) is one of the most important parameters that can be provided an experimenter. To be able to measure accurately the NVT for various conditions of pulse width and pulse tail energy contribution aids in understanding experiment and reactor phenomena.

Shown in Figure 5 is a circuit which is. very simple in construction and low in cost. The key to the system is the self-powered rhodium detector. Rhodium detectors use natural rhodium (over 99\% Rh 103) which has a very high thermal neutron absorption cross section. Rhodium 103 plus a neutron produces Rh 104 and decays by a beta emission with a 42 second half-life. It is this negatively charged beta particle that produces the desired signal current. During a reactor pulse, eleclruns are pruduced in the detector materlals from the gamma photons (Compton eftect), but this prompt gamma effect is undesirable for use in evaluating the neutron pulse fluence on a slowmoving strip chart recorder or peak reading voltmeter as described in the last section. The desirable kind of signal from a detector is representative of the neutrons the rhodium sees during and shortly after the pulse (pulse tail). Indicated in Figure 5 is the type of signal seen in different parte of the circuit with various time seales.

The objectives in altering the signal from the rhodium detector to produce an accurate NVT signal are:

1. To produce a peak output which is proportional to NVT and accurately measurable on the console strip chart recorder

2. To place the peak output late enough in time to allow for accumulation of neutrons from tail energy ( 2 seconds after the pulse) and to evaluate a multiple-pulse operation with time between pulses of about 1 second. 
TABLE II

ACPR Reactor Peak Power Detector System Specifications and Costs

Specifications:

Burr- $\frac{\text { Beak Detector }}{\text { Brown Mod. } 4084 / 25}$

- Analog Inputs:

$\begin{array}{ll}\text { Signal } & \pm 10 \mathrm{~V} \\ \text { Maximum } & \pm 15 \mathrm{~V} \\ \text { Input Bias I } & 600 \mathrm{nA} \\ \text { Input } Z & 50 \mathrm{M} \Omega\end{array}$

- Digital Inputs

Logic Level

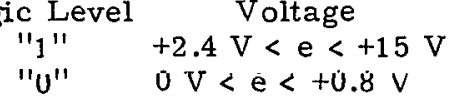

- Transfer Characteriaticg

Accuracy

Voltage Gain $\quad 1.0 \mathrm{~V} / \mathrm{V}$

Gain Accuracy dc $\pm 1 \mathrm{mV}$

Stability

dc to $100 \mathrm{~Hz} \quad \pm 2 \mathrm{mV}$

Droop (aftcr detecting a .

peak or in hold $0^{\circ}$ to $25^{\circ} \mathrm{C}$ ) $\pm 5 \mathrm{mV} / \mathrm{s}$

Switching Performance

Output Slew Rate $1 \mathrm{~V} / \mu \mathrm{s}$
- Output

$\begin{array}{lcc}\text { Analog } & \pm 10 \mathrm{~V} & \pm 5 \mathrm{~mA} \\ \text { Impedance } & 0.05 \Omega & \\ \text { Noise de to } & 10 \mathrm{kHz} & 0.1 \mathrm{mV} \text { rms } \\ \text { Digital } & \text { TTL/DT L Compatable }\end{array}$

4-Digit Panel Meter

Non-Linear Sys.. Model P M-4.

- Range : \pm 10 Volt

- Accuracy : $\pm 0.02 \%$ F.S. $(2 \mathrm{mV}$ )

- Settle 'l'ime : 2 seconds max.

- Speçd ; 2 Readings/second

Intcg. Timc : $100 \mathrm{~ms}$

- Power : +5 Vdc $15 \%$ @ $160 \mathrm{~mA}$

- Size (in.) : $15 / 16 \mathrm{H} \times 2-1 / 2 \mathrm{~W} \times$ $3-1 / 4 \mathrm{D}$

- Temp. Coef. : $\pm(0.005 \% \mathrm{rdg}+0.001 \%$ F.S.) $/{ }^{\circ} \mathrm{C}$

- Input Z : $1 \mathrm{M} \Omega$

- C.M.R. : $80 \mathrm{~dB}$ min.

- Control Signal or Hold Line to Inhibit Readings

- Decimal Location Control by Jumper
Part No./ Name

Peak Detector

P. D. Connector

D.P.M.-PM-4

D.P.M. Connector

MC $846 \mathrm{P}$ Gate

SN74121N M.V.

NE $555 \mathrm{~V}$ Timer

MC 848 P.F.F.

MC 858P Gate

W118 Dip-5 Relay

MC836P Inv.

Sockets

MTIL-CO6- 1 T

$\pm 15 \mathrm{~V}$ Pwr. Sup.

$\pm 5 \vee$ Pwr. Sup.

Miec. Switchec,

Connec., \& Panel

Total Cost
Costs:

\begin{tabular}{lr}
\multicolumn{1}{c}{ Manufacturer } & Cost \\
\hline Burr-Brown & 145.00 \\
Burr-Brown & 10.00 \\
Non-Linear Sys. & 70.00 \\
Non-Linear & 5.00 \\
Motorola & .90 \\
Texas Inst. & 1.06 \\
Signetics & 1.50 \\
Motorola & 2.50 \\
Motorola & .90 \\
Magnacraft & 8.50 \\
Motorola & 1.00 \\
& (8) 4.00 \\
Tec Lite & 5.75 \\
& 45.00 \\
& 45.00 \\
& \\
& \\
&
\end{tabular}




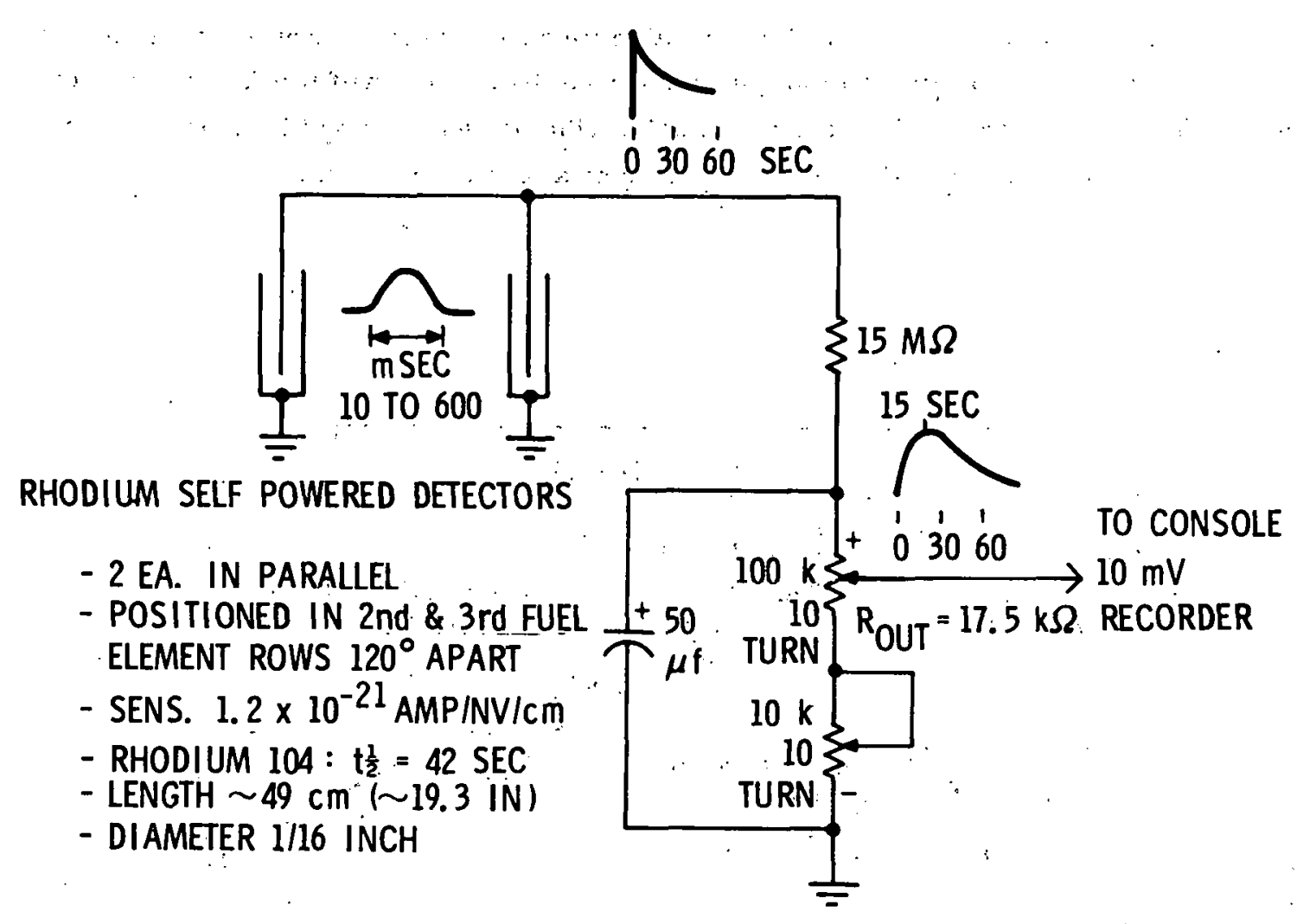

Figure 5. ACPR Pulse Fluence (NVT) Measuring Circuit

3. To provide a peak amplitude that is usable for a shutdown signal soon after the pulse

4. To be accurate over the full range of ACPR pulsing $\left(\$ 1\right.$ to $\$ 4.50$, or $5 \times 10^{12}$ to $1.8 \times 10^{15}$ NVT, neutron energies $E>10 \mathrm{keV}$ )

5. To filter out the gamma-induced pulse.

Resistance is used to develop the voltage proportional to the neutron induced current, and a bypass capacitor is sized to pass the gamma pulse while it also acts to charge and produce a. peak proportional to NVT. With the component sizes listed, the peak occurs about 15 . seconds after the pulse. This satisfies objectives $1,2,3$, and 5 above. Accuracy has been verified in over three years of operation throughout the entire range of pulse capability and by two complete ACPR recalibrations with new core configurations. Figure 6 illustrates the affect of capacitor size on the time to peak signal after a pulse, as well as the affects on the rhodium decay. The $50 \mu \mathrm{F}$ capacitor was chosen as the best size to satisfy all the design objectives. A pulse of just slightly over $\$ 1$ produces a pulse width of $\sim 800 \mathrm{~ms}$ at the base. The reactance the capacitor offers to this pulse is about $5 \mathrm{k} \Omega$ and is much less than the resistors sized to provide NVT output. Figure 7 was included to show that nver $f$ wirte range of pulsing, $\$ 2$ to $\$ 1.10$, the NVT peak jocurs about the same time 
and the basic rhodium decay signal is unaffected. Also illustrated is an evaluation of the rhodium decay without any bypass capacitance to measure a normal decay. The half life for the detector was measured at 46.3 seconds. This does not coincide with the published half life, but reveals that the $50 \mu \mathrm{F}$. capacitor does not affect the decay scheme after the NVT peak. .

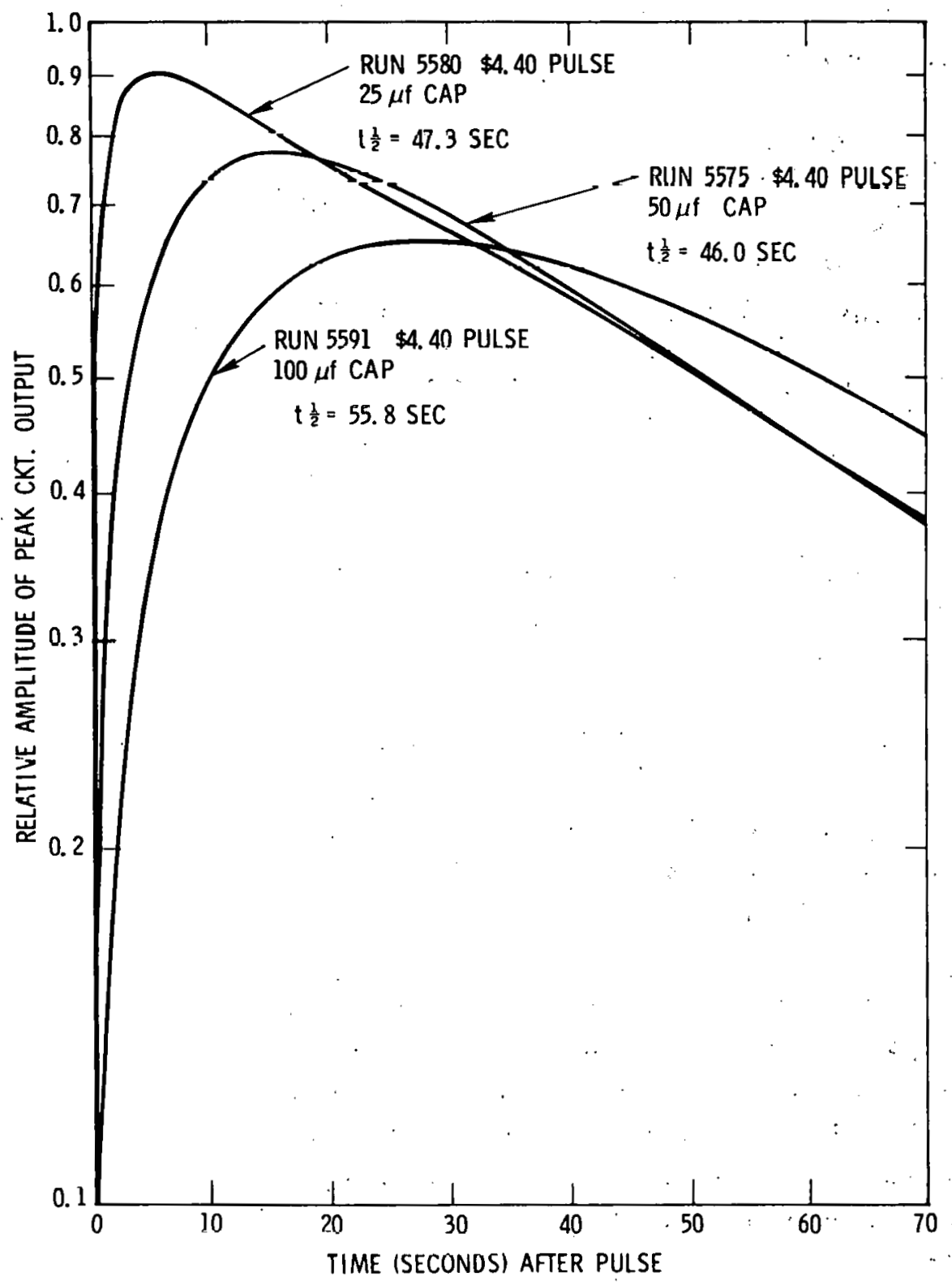

Figure 6. NVT Peak Detector Response for Different Storage Capacitor Sizes 


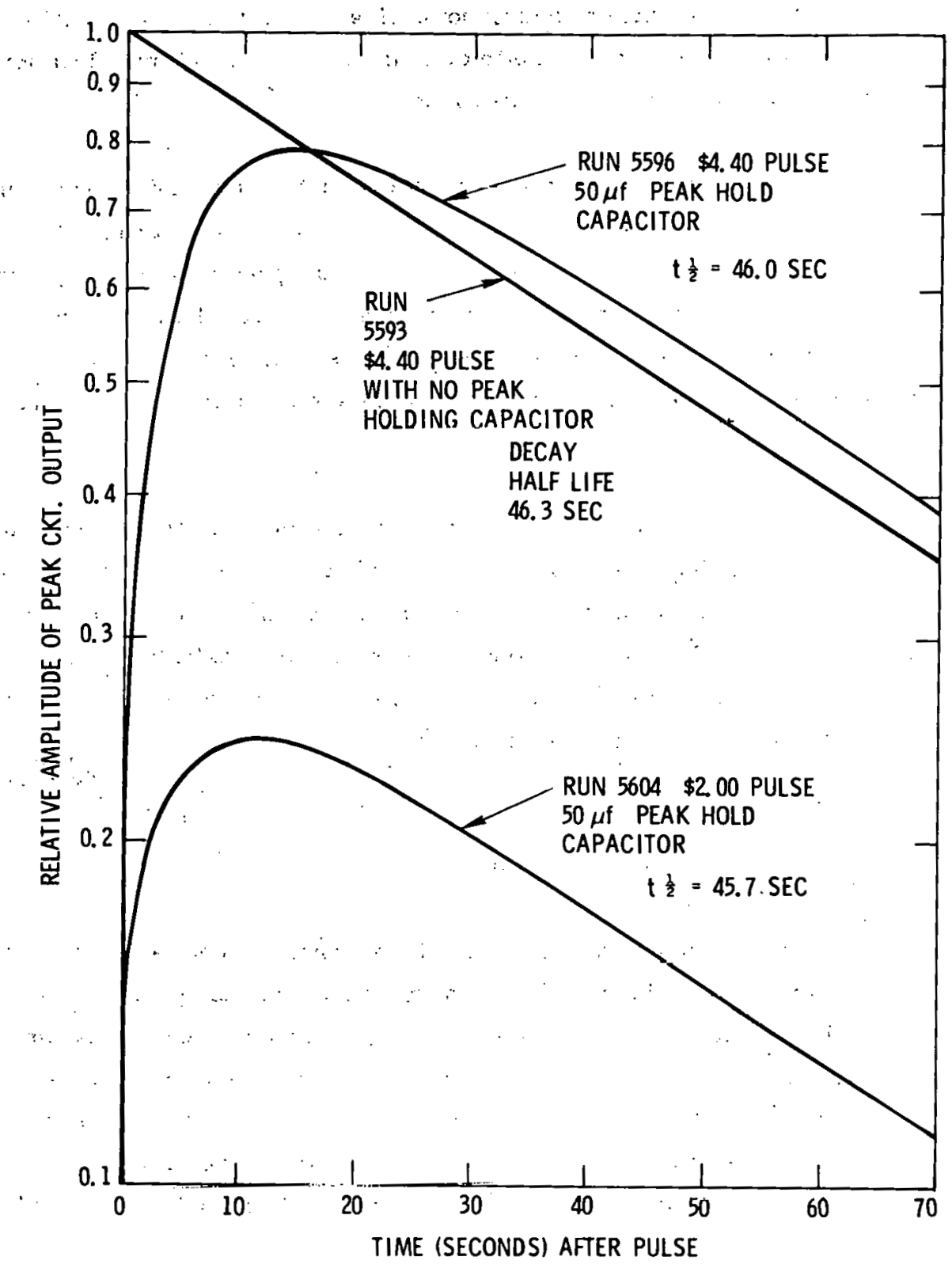

Figure 7. NVT Peak Detector Response for Different Pulse Sizes 
The basic cost of the system is about $\$ 600$ for two rhodium detectors. Two detectors are necessary to average out the affects of tilting and to provide a larger output current. The ACPR detectors are located inside the fuel elements; this is not desirable because the high fuel temperatures reduce the detector resistance and useful lifetime. It is also not the optimum location for a large thermal neutron population since it is too close to the fuel.

Calibration - - In preparing to calibrate the system, the detector(s) should be placed next to the experiment irradiation space and, if two are used, so oriented that any tilting effects will average out in the detector output sum. The NVT to the experiment space is of primary importance, not the reactor energy release, but this system can also be used to establish the core energy release from a pulse since NVT is directly proportional to the pulse fluence; in such cases it is particularly impnrtant that two detectors be positioned so that the effects of flux tilting are averaged out.

To calibrate the output signal for console recorder accuracy, the potentiometers must first be set at some known resistance. Then a known pulac io produced. From lhe satio of the lenown to the recorded NVT, the desired voltage on the recorder can be obtained, then the required resistance derived. The pots are set for this new value and another pulse test conducted to check the accuracy of the setting. Note that of the two pots, the $10 \mathrm{k} \Omega$ pot provides the needed 3-place resolution. (See Dwg. T40886 in the Appendix for other details.)

\section{Surmary}

These circuit designs have been used to yield reliable information about ACPR operations for a significant period of time. After the initial calibration of the circuits, periodic checks have shown no need for subsequent changes. The systems were low in price and easy to assemble. The reactor period measuring system is useful in evaluating reactivity additions as amull as a few cents and pulses as large as $\$ 4.50$. Reactor peak power detection has been found to he accurate to three significant figures and over the entire range of ACPR pulsing. The pulse fluence detector is simple, dependable. and accurate, with a broad operating range of $5 \times 10^{12}$ to $1.0 \times 10^{15} \mathrm{NVT}$ $(\mathrm{E}>10 \mathrm{keV})$. 
APPENDDX

Sandia Drawings 


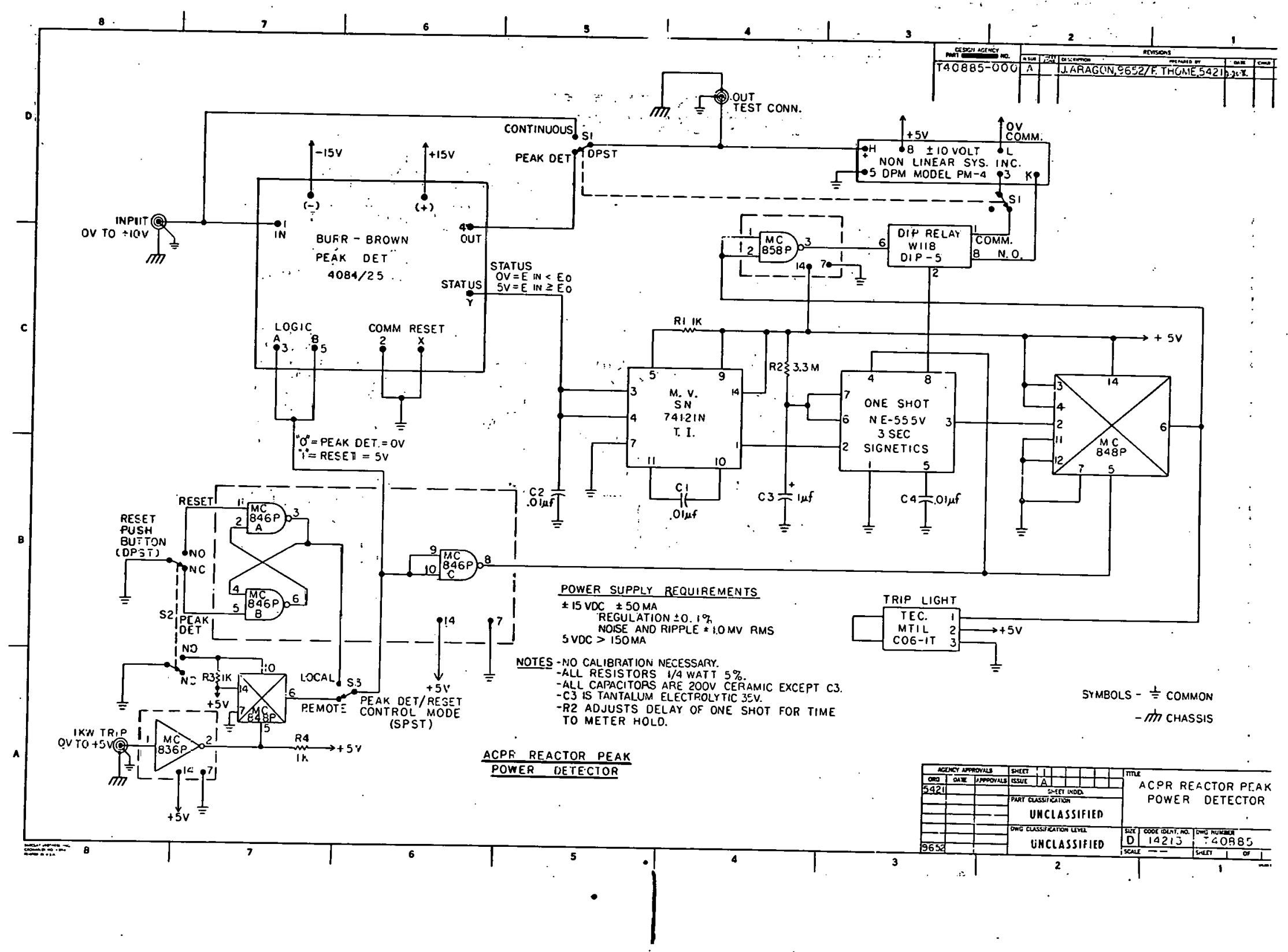




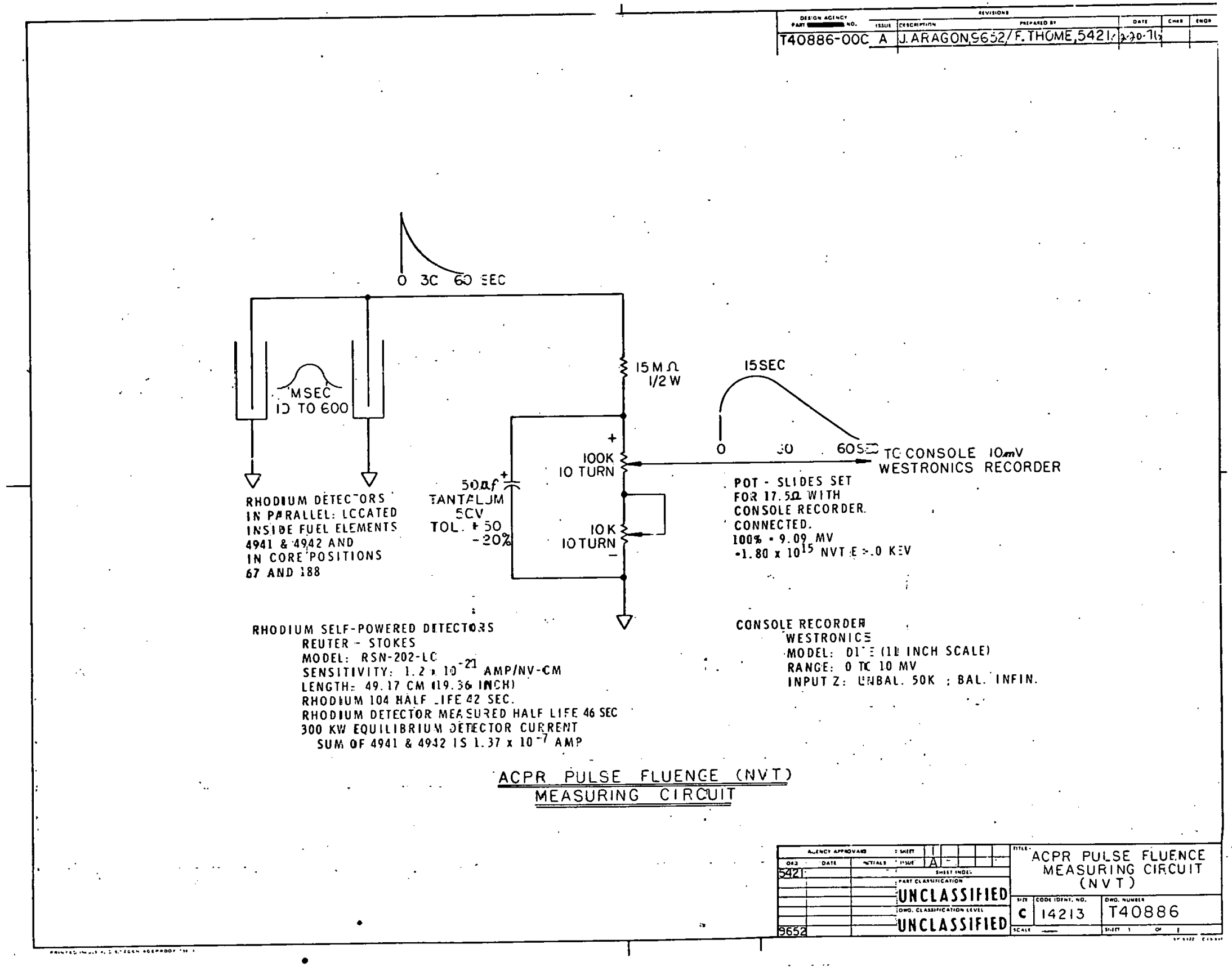




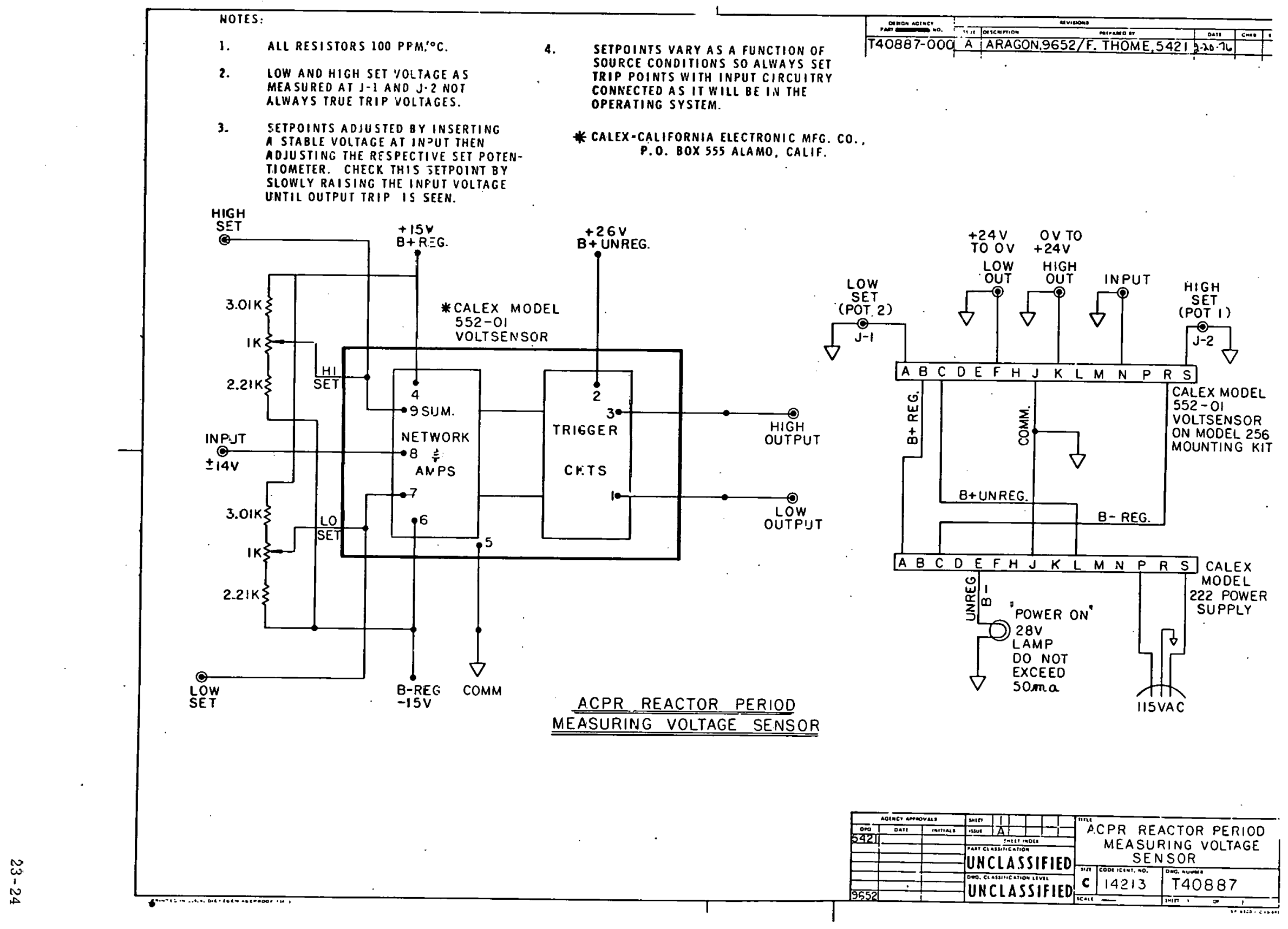


US Energy Res, and Dev. Adm. Division of Operational Safety

Washington, DC 20545

Attn: M. A. Bell

US Energy Res. and Dev.. Adm. (4) Albuquerque Operations Office P. O. Box 5400

Albuquerque, NM 87115.

Attn: K. E. Elliott

US Energy Res, and Dev. Adm. Sandia Area Office

P. O. Box 5400

Albuquerque, NM 87115.

Attn: R. R. Malone

University of Arizona

Nuclear Engineering Department

Tucson, AZ 85721

Attn: R. L. Seale

University of California

Department of Nuclear Engineering

Berkeley, CA 94720

University of California

Department of Nuclear Engineering Irvine, CA 92664

University of California

Department of Nuclear Engineering Santa Barbara, CA 03106

University of California

Lawrence Livermore Laboratory

P. O. Box 808

Livermore, CA 94550

Attn: Reports Library

University of Cincinnati

Department of Nuclear Engineering

Cincinnati, OH 45221

Attn: H. J. Leonard

Columbia University

164 Engineering Terrace

New York, NY 10027

Attn: Reports Library

Cornell University

Department of Nuclear Engineering

Ithaca, NY 14850

Defense Nuclear Agency

Commander Field Command

Kirtland Air Force Base

Albuquerque, NM 87115
Dow Chemical Company

TRIGA Operations Group

Midland, MI 48640

U. S. Geological Survey Laboratory

Department of Interior

Denver, CO 80200

General Atomic Company (6)

P. O. Box 608

San Diego, CA 92112

Attn: F. C. Foushee

G. C. Law

G. B. West

R. Peters

W. K. Hyde

W. Whittemore

Harry Diamond Laboratories

Washington, DC 20438

Attn: W. L. Gieseler

University of Mlinois (2)

Nuclear Engineering Department

Urbana, IL 61801

Attn: M. E. Wyman

G. P. Beck

Kansas State University

Department of Nuclear Engineering

Manhattan, KS 66502

Los Alamos Scientific Laboratory (2)

P. O. Box 1663

Los Alamos. NM 87544

Attn: Reports Library

H. T. Williams

Michigan State University

Department of Nuclear Engineering

East Lansing, MI 48823

University of New Mexico (2)

Department of Nuclear Engineering

Albuquerque, NM 87106

Attn: G. A. Whan

Northrop Corporate Laboratories

Space Radiation Laboratory

Hawthorne, CA 90250

Omaha Veterans Administration Hospital

TRIGA Reactor Operations Group

Omaha, NB 68105

Oregon State University

Department of Nuclear Engineering

Corvallis, OR 97331 
Reed College

Engineering Department

Portland, OR 97202

Attn: TRIGA Operations

Stanford Research Institute

333 Ravenswood Avenue

Menlo Park, CA 94025

Attn: Reports Library

University of Texas

Department of Nuclear Engineering

Austin, TX 78712

Texas A\&M University

Nuclear Science Center Reactor

College Station, TY 77843

University of Wisconsin

Department of Nuclear Engineering

Madison, WI 53703

Attn: C. W. Maynard

Virginia Polytechnic Institute

Blacksburg, VA 24001

Attn: R. T. Stone

Washington State University (2)

Nuclear Radiation Center

Pullman, WA 99163

Attn: G. W. Hinman

W. E. Wilson

Japan Atomic Energy Research Institute Chief, Reactivity Accident Laboratory Division of Reactor Safcty

Tokai Research Fistahlishment

Tokai - Mura.

Naka-Gun Ibaraki-Ken, Japan

Attn: Dr. Mi.chio Ishikawa
1700

1730

1739

1739

5000

5400

5420

5422

5423

5423

5430

5450

5451

5451

5451

5451

5451

5451

5451

5451

5451

5452 .

5452

5452

5152

5452

5712

5712

8266

3141

3151

$$
\text { ERDA/TIC (25) }
$$

D. E. Jones

W. C. Myre

J. D. Williams

F. V. Thomé (20)

A. Narath

A. W. Snyder

J. V. Walker

R. L. Coats

J. E. Powell

H. L. Kefauver

R. M. Jefferson

J. A. Reuscher

T. R. Schmidt

K. Boldt

J. C. Conant

B. F. E'stes

V. F.. James

G. L. Scott,

J. A. Snyder

R. T... Williams (10)

J. L. Zubersky

I.. D. Posey

A. C. Marehall

F. M. Morris

J. S. Philbin

P. S. Pickard

J. A. Leonard

R. D. Meyer (10)

E. A. Aas

C. A. Pepmueller (Actg) (5)

W. L. Garner (3)

For: ERDA/TIC (Unlimited Release)

(R. P. Campbell, 3172-3) 